\title{
Predictors of all-cause and cardiovascular disease mortality in type 2 diabetes: Diabetes Heart Study
}

\author{
Laura M. Raffield ${ }^{1,2,3}$, Fang-Chi Hsu ${ }^{4}$, Amanda J. Cox ${ }^{2,3,5}$, J. Jeffrey Carr ${ }^{6}$, Barry I. Freedman ${ }^{7}$ and Donald W. Bowden ${ }^{2,3,5,8^{*}}$
}

\begin{abstract}
Background: Many studies evaluated the best predictors for cardiovascular disease (CVD) events in individuals with type 2 diabetes (T2D), but few studies examined the factors most strongly associated with mortality in T2D. The Diabetes Heart Study (DHS), an intensively phenotyped family-based cohort enriched for T2D, provided an opportunity to address this question.
\end{abstract}

Methods: Associations with mortality were examined in 1022 European Americans affected by T2D from 476 DHS families. All-cause mortality was $31.2 \%$ over an average 9.6 years of follow-up. Cox proportional hazards models with sandwichbased variance estimation were used to evaluate associations between all-cause and CVD mortality and 24 demographic and clinical factors, including coronary artery calcified plaque (CAC), carotid artery intima-media thickness, medications, body mass index, waist hip ratio, lipids, blood pressure, kidney function, QT interval, educational attainment, and glycemic control. Nominally significant factors $(p<0.25)$ from univariate analyses were included in model selection (backward elimination, forward selection, and stepwise selection). Age and sex were included in all models.

Results: The all-cause mortality model selected from the full DHS sample included age, sex, CAC, urine albumin: creatinine ratio (UACR), insulin use, current smoking, and educational attainment. The CVD mortality model selected from the full sample included age, sex, CAC, UACR, triglycerides, and history of CVD events. Beyond age, the most significant associations for both mortality models were CAC $\left(2.03 \times 10^{-4} \leq p \leq 0.001\right)$ and UACR $\left(1.99 \times 10^{-8} \leq p \leq\right.$ $2.23 \times 10^{-8}$ ). To confirm the validity of the main predictors identified with model selection using the full sample, a two-fold cross-validation approach was used, and similar results were observed.

Conclusions: This analysis highlights important demographic and clinical factors, notably CAC and albuminuria, which predict mortality in the general population of patients with T2D.

Keywords: Type 2 diabetes, Mortality, Coronary artery calcified plaque, Urine albumin:creatinine ratio

\section{Background}

The Diabetes Heart Study (DHS) is an ongoing familybased cohort study investigating the epidemiology and genetics of cardiovascular disease (CVD) in a population-based sample. Prior analyses in this type 2 diabetes (T2D)-enriched cohort [1] have individually examined contributors to allcause and CVD mortality. Coronary artery calcified atherosclerotic plaque (CAC), a measure of subclinical CVD [2, 3],

\footnotetext{
* Correspondence: dbowden@wakehealth.edu

${ }^{2}$ Center for Human Genomics, Wake Forest School of Medicine,

Winston-Salem, NC, USA

${ }^{3}$ Center for Diabetes Research, Wake Forest School of Medicine,

Winston-Salem, NC, USA

Full list of author information is available at the end of the article
}

C-reactive protein (CRP) [4], biventricular volume [5], heart rate-corrected electrocardiographic QT interval [6], serum albumin and creatine, estimated glomerular filtration rate (eGFR), and urine albumin:creatinine ratio (UACR) [7] were all found to predict mortality in the DHS.

Prior studies have examined risk prediction scores for CVD events in patients with T2D [8,9], which is an important contributor to mortality [10]. However, fewer studies have attempted to evaluate the best predictors of all-cause and CVD mortality in T2D [11-14]. We performed a comprehensive analysis of which factors were the strongest independent predictors of all-cause and CVD mortality using model selection (backward 
elimination, forward selection, and stepwise selection) in European Americans (EAs) with T2D from the DHS.

\section{Methods}

\section{Study design and sample}

The DHS recruited T2D-affected siblings without advanced renal insufficiency from 1998 through 2005 in western North Carolina. T2D was defined as diabetes developing after the age of 35 years initially treated with changes in diet and exercise and/or oral agents, in the absence of historical evidence of ketoacidosis or initial treatment with insulin. Fasting glucose and glycated hemoglobin $\left(\mathrm{HbA}_{1 \mathrm{c}}\right)$ concentrations were assessed at the exam visit. Ascertainment and recruitment criteria have been described [1]. DHS participants were recruited from the general population and broadly reflect the demography of T2D in our community. Importantly, prior evidence of CVD was not an exclusion to participate. All study protocols were approved by the Institutional Review Board at Wake Forest School of Medicine, and all participants provided written informed consent.

Participant examinations were conducted in the General Clinical Research Center of Wake Forest Baptist Medical Center. Examinations included interviews for medical history and health behaviors, anthropometric measures, resting blood pressure, electrocardiography, fasting blood sampling for laboratory analyses, and spot urine collection. Low-density lipoprotein (LDL) cholesterol was calculated using the Friedewald equation, and LDL measures were considered valid for subjects whose triglycerides were less than $400 \mathrm{mg} / \mathrm{dL}$. Estimated glomerular filtration rate (eGFR) was computed using the CKD-EPI equation [15]. CAC was assessed using computed tomography $(\mathrm{CT})$, summing the left main, left anterior descending, circumflex, posterior descending, and right coronary arteries. CT scans were performed on multi-detector CT scanners with cardiac gating in chest scans. CAC scores were measured as previously described and validated [16, 17]. Data on prior CVD events was self-reported by participants and non-adjudicated. Individuals were considered to have a history of prior CVD if they self-reported prior MI, angina, stroke, or vascular procedures including coronary angioplasty, coronary artery bypass graft, or endarterectomy, or if they had Q wave abnormalities indicative of prior MI.

Mortality was assessed using the National Social Security Death Index. For deceased participants, length of follow-up was determined from the date of initial study visit to date of death. For all other participants the length of follow-up was determined from the date of the initial study visit to December 31, 2013. When possible, copies of death certificates were obtained from county or state Vital Records Offices to determine cause of death. Both all-cause and CVD mortality were analyzed; cause of death was categorized based on death certificates as CVD mortality (myocardial infarction, congestive heart failure, cardiac arrhythmia, sudden cardiac death, peripheral vascular disease, and stroke) or as mortality from other causes. For 18 patients, cause of death information could not be obtained, so these participants were excluded from analyses of CVD mortality.

\section{Statistical methods}

Cox proportional hazards models with sandwich-based variance estimation (due to the family structure of the DHS) in SAS 9.3 were used to evaluate associations with mortality. For model building, 24 potential predictors of mortality for which data was available for most individuals in the cohort, including CAC, carotid artery intima media thickness (IMT), medications, body mass index (BMI), waist hip ratio (WHR), lipids, blood pressure, kidney function measures, electrocardiographic QT interval, educational attainment, and glycemic control measures, were evaluated in separate models for their association with all-cause mortality and CVD mortality. Variables were transformed prior to analysis; the square root of BMI and high-density lipoprotein (HDL) cholesterol, the square of WHR, and the natural $\log$ of glucose, $\mathrm{HbA}_{1 \mathrm{c}}, \mathrm{CAC}$, total cholesterol, triglycerides, UACR, QT interval, diabetes duration, IMT, and mean arterial pressure were used. Nominally significant factors $(p<0.25)$ from univariate analyses were included in model selection performed in SAS 9.3. We confirmed that no factors included in model selection were strongly correlated $(r>0.8)$. Age and sex were included in all models. For backward elimination selection, factors with a $p$-value $<0.05$ for association with mortality were retained in the model. For stepwise selection, factors meeting a threshold of a $p$-value $<0.25$ could enter into the model but required a $p$-value $<0.05$ to be retained. For forward selection, factors meeting a threshold of a $p$-value $<0.05$ could enter into the model. In our analysis, results from the multiple Cox regression models were concordant for forward, backward, and stepwise model selections. Calculations for area under the receiver operating characteristic curve (AUC) were performed in STATA version 12.1.

\section{Results}

All self-described EAs from the DHS with T2D (1022 individuals from 476 families) were included in the analyses. Table 1 displays their demographic and clinical characteristics, presented for the full sample and stratified by mortality status. For the full cohort, mean \pm standard deviation (SD) diabetes duration was 10.4 \pm 7.2 years. Prevalence of hypertension, obesity, subclinical CVD based on CAC, and prior CVD events were high. Over a mean \pm SD follow-up of $9.6 \pm 3.2$ years, all-cause mortality was $31.2 \%$ and CVD mortality was $14.3 \%$. 
Table 1 Demographic and clinical characteristics of European American participants with type 2 diabetes, stratified by mortality status

\begin{tabular}{|c|c|c|c|c|c|c|}
\hline \multirow[b]{2}{*}{ Trait } & \multicolumn{2}{|c|}{ Full Sample $(n=1022)$} & \multicolumn{2}{|l|}{ Living $(n=703)$} & \multicolumn{2}{|c|}{ Deceased $(n=319)$} \\
\hline & Mean (SD) or \% & Median (range) & Mean (SD) or \% & Median (range) & Mean (SD) or \% & Median (range) \\
\hline Age (years) & $62.43(9.07)$ & $62.80(34.21,85.98)$ & $60.64(8.48)$ & $60.54(34.21,81.77)$ & $66.36(9.09)$ & $67.03(34.34,85.98)$ \\
\hline Female Sex (\%) & $51.5 \%$ & & $54.8 \%$ & & $44.2 \%$ & \\
\hline Current Smoking (\%) & $16.1 \%$ & & $14.0 \%$ & & $20.8 \%$ & \\
\hline Past Smoking (\%) & $43.4 \%$ & & $43.6 \%$ & & $43.1 \%$ & \\
\hline History of Cardiovascular Disease (\%) & $43.2 \%$ & & $37.3 \%$ & & $56.1 \%$ & \\
\hline All-Cause Mortality (\%) & $31.2 \%$ & & $0 \%$ & & $100 \%$ & \\
\hline Cardiovascular Disease Mortality (\%) & $14.3 \%$ & & $0 \%$ & & $47.8 \%$ & \\
\hline Educational Attainment- Less than High School (\%) & $25.6 \%$ & & $20.8 \%$ & & $36.4 \%$ & \\
\hline Educational Attainment- High School (\%) & $49.2 \%$ & & $51.4 \%$ & & $44.1 \%$ & \\
\hline Educational Attainment- Greater than High School (\%) & $25.2 \%$ & & $27.8 \%$ & & $19.5 \%$ & \\
\hline Body Mass Index $\left(\mathrm{kg} / \mathrm{m}^{2}\right)$ & $32.38(6.58)$ & $31.32(17.10,57.97)$ & $32.67(6.40)$ & $31.61(17.10,57.97)$ & $31.75(6.93)$ & $30.54(17.54,56.92)$ \\
\hline Waist Hip Ratio & $0.941(0.082)$ & $0.944(0.436,1.246)$ & $0.937(0.077)$ & $0.939(0.648,1.234)$ & $0.949(0.091)$ & $0.955(0.436,1.246)$ \\
\hline Glucose (mg/dL) & $147.9(56.15)$ & $135(16,463)$ & $145.6(51.17)$ & $134(16,463)$ & $152.9(65.60)$ & $140(46,436)$ \\
\hline Glycated Hemoglobin (\%) & $7.60(1.72)$ & $7.20(4.30,18.30)$ & $7.49(1.61)$ & $7.10(4.60,16.40)$ & $7.84(1.92)$ & $7.60(4.30,18.30)$ \\
\hline Diabetes Duration (years) & $10.42(7.15)$ & $8(0,46)$ & $9.32(6.39)$ & $7(0,46)$ & $12.80(8.09)$ & $11(1,41)$ \\
\hline Coronary Artery Calcified Plaque (mass score) & $1856(3335)$ & $449.5(0,50415)$ & $1328(3038)$ & $256.5(0,50415)$ & $3048(3657)$ & $1632(0,22378)$ \\
\hline Carotid Intima Media Thickness (mm) & $0.683(0.136)$ & $0.659(0.449,1.569)$ & $0.664(0.127)$ & $0.639(0.449,1.569)$ & $0.723(0.144)$ & $0.700(0.456,1.316)$ \\
\hline Total Cholesterol (mg/dL) & $185.2(43.42)$ & $181(65,427)$ & $184.5(43.15)$ & $180(65,427)$ & $186.9(44.04)$ & $183(70,386)$ \\
\hline $\mathrm{HDL}(\mathrm{mg} / \mathrm{dL})$ & $42.16(11.89)$ & $41(8,98)$ & $42.46(11.59)$ & $41(14,94)$ & $41.49(12.52)$ & $40(8,98)$ \\
\hline Triglycerides (mg/dL) & $208.9(138.8)$ & $176(30,1310)$ & $206.0(136.4)$ & $173(30,1310)$ & $215.3(143.9)$ & $183(30,1065)$ \\
\hline $\mathrm{LDL}(\mathrm{mg} / \mathrm{dL})$ & $103.0(32.6)$ & $100(12,236)$ & $102.2(32.4)$ & $100(14,207)$ & $104.9(33.1)$ & $103(12,236)$ \\
\hline Pulse Pressure (mmHg) & $67.09(16.93)$ & $65.5(28,159)$ & $65.53(15.85)$ & $64(28,124)$ & $70.52(18.67)$ & $69.5(31,159)$ \\
\hline Mean Arterial Pressure $(\mathrm{mmHg})$ & $95.05(11.24)$ & $94(66.5,154)$ & $95.19(10.33)$ & $94(66.5,140.3)$ & $94.75(13.02)$ & $93.17(67.33,154)$ \\
\hline Estimated Glomerular Filtration Rate $\left(\mathrm{ml} / \mathrm{min} / 1.73 \mathrm{~m}^{2}\right)$ & $65.76(18.38)$ & $63.77(8.91,126.4)$ & $67.95(17.86)$ & $65.43(20.97,122.2)$ & $60.96(18.62)$ & $58.43(8.91,126.4)$ \\
\hline Urine Albumin:creatinine Ratio (mg/g) & $121.5(530.5)$ & $14.29(0.48,9449)$ & $68.49(390.8)$ & $11.57(0.48,8878)$ & $239.8(741.5)$ & $23.08(0.78,9449)$ \\
\hline QT Interval (ms) & $393.8(33.14)$ & $392.0(270.1,564.0)$ & $393.2(32.27)$ & $392.0(310.1,564.0)$ & $395.0(34.93)$ & $392.0(270.1,526.0)$ \\
\hline High Blood Pressure Medications (\%) & $75.5 \%$ & & $72.0 \%$ & & $83.4 \%$ & \\
\hline Statin Use (\%) & $42.7 \%$ & & $44.8 \%$ & & $37.9 \%$ & \\
\hline Oral Hypoglycemic Medications (\%) & $78.8 \%$ & & $79.0 \%$ & & $78.4 \%$ & \\
\hline Insulin Use (\%) & $27.3 \%$ & & $22.9 \%$ & & $37.0 \%$ & \\
\hline C-reactive Protein (mg/dL) & $0.611(1.004)$ & $0.296(0.005,12.73)$ & $0.529(0.793)$ & $0.28(0.005,9.573)$ & $0.801(1.355)$ & $0.353(0.008,12.73)$ \\
\hline Biventricular Volume (ml) & $384.5(112.1)$ & $375.6(156.6,884.5)$ & $372.0(100.7)$ & $361.3(156.6,781.8)$ & $411.8(129.7)$ & $397.2(182.6,884.5)$ \\
\hline
\end{tabular}


The univariate associations of demographic and clinical factors with all-cause and CVD mortality in the full EA T2D-affected cohort are shown in Table 2. Demographic and clinical factors were selected for model selection based on their associations with all-cause or CVD mortality $(p<0.25)$ (Table 2). Based on these univariate associations, model selection for all-cause mortality included $\mathrm{HbA}_{1 \mathrm{c}}, \mathrm{CAC}$, pulse pressure, HDL, eGFR, UACR, diabetes duration, $\mathrm{BMI}$, high blood pressure medication use, insulin use, current smoking, history of CVD, educational attainment (less than high school, high school, greater than high school), WHR, mean arterial pressure, and IMT. Model selection for CVD mortality included fasting glucose, $\mathrm{HbA}_{1 \mathrm{c}}$, CAC, pulse pressure, $\mathrm{HDL}$, triglycerides, eGFR, UACR, QT interval, diabetes duration, BMI, high blood pressure medication use, insulin use, history of CVD, educational attainment, WHR, and IMT.
The all-cause mortality model selected from the full sample included age, sex, CAC, UACR, insulin use, current smoking, and educational attainment (Table 3). Other than age, the most significant associations with all-cause mortality were for CAC $\left(p=2.03 \times 10^{-4}\right.$, hazard ratio $(\mathrm{HR})=1.48$ for a standard deviation (SD) change) and UACR $\left(p=2.23 \times 10^{-8}, \mathrm{HR}=1.37\right.$ for a SD change). The CVD mortality model selected from the full sample included age, sex, CAC, UACR, triglycerides, and history of CVD (Table 3). Similar to the all-cause mortality analysis, other than age, the most significant associations with CVD mortality were for CAC $(p=0.001, \mathrm{HR}=1.71$ for a SD change) and UACR $\left(p=1.99 \times 10^{-8}, \mathrm{HR}=1.51\right.$ for a SD change).

To confirm the validity of the most important predictors identified with model selection using the full DHS sample, a two-fold cross-validation approach was used,

Table 2 Associations of demographic and clinical factors with all-cause and cardiovascular disease (CVD) mortality

\begin{tabular}{|c|c|c|c|c|c|c|c|c|c|c|}
\hline \multirow{3}{*}{$\frac{\text { Trait }}{\text { Age (years) }}$} & \multicolumn{5}{|c|}{ All-cause Mortality } & \multicolumn{5}{|c|}{ CVD mortality } \\
\hline & \multirow{2}{*}{$\frac{\mathrm{HR}}{1.86}$} & \multicolumn{2}{|c|}{$95 \% \mathrm{HR} \mathrm{Cl}$} & \multirow{2}{*}{$\frac{p \text {-value }}{<1 \times 10^{-16}}$} & \multirow{2}{*}{$\frac{n}{1022}$} & \multirow{2}{*}{$\frac{\mathrm{HR}}{1.74}$} & \multicolumn{2}{|c|}{$95 \% \mathrm{HRCl}$} & \multirow{2}{*}{$\frac{p \text {-value }}{1.40 \times 10^{-7}}$} & \multirow{2}{*}{$\frac{n}{1004}$} \\
\hline & & 1.62 & 2.13 & & & & 1.41 & 2.13 & & \\
\hline Female Sex (\%) & 0.68 & 0.54 & 0.85 & $8.83 \times 10^{-4}$ & 1022 & 0.58 & 0.41 & 0.82 & 0.002 & 1004 \\
\hline Current Smoking (\%) & 1.44 & 1.11 & 1.88 & 0.006 & 1018 & 1.04 & 0.66 & 1.63 & 0.866 & 1000 \\
\hline Past Smoking (\%) & 0.99 & 0.79 & 1.23 & 0.896 & 1018 & 1.13 & 0.82 & 1.57 & 0.452 & 1000 \\
\hline History of Cardiovascular Disease (\%) & 1.91 & 1.52 & 2.41 & $3.86 \times 10^{-8}$ & 1013 & 3.25 & 2.25 & 4.69 & $3.21 \times 10^{-10}$ & 995 \\
\hline Educational attainment (3 levels) & 0.68 & 0.58 & 0.81 & $1.73 \times 10^{-5}$ & 1011 & 0.74 & 0.58 & 0.95 & 0.02 & 993 \\
\hline dy Mass Index $\left(\mathrm{kg} / \mathrm{m}^{2}\right)$ & 0.87 & 0.77 & 0.99 & 0.033 & 1022 & 0.89 & 0.74 & 1.07 & 0.225 & 1004 \\
\hline Waist Hip Ratio & 1.16 & 1.02 & 1.32 & 0.029 & 1012 & 1.2 & 1 & 1.45 & 0.049 & 994 \\
\hline Glucose (mg/dL) & 1.04 & 0.92 & 1.17 & 0.512 & 1020 & 1.16 & 0.98 & 1.38 & 0.089 & 1002 \\
\hline Glycated Hemoglobin (\%) & 1.09 & 0.97 & 1.22 & 0.169 & 1016 & 1.23 & 1.06 & 1.43 & 0.008 & 998 \\
\hline Diabetes duration (years) & 1.54 & 1.36 & 1.74 & $5.62 \times 10^{-12}$ & 1005 & 1.7 & 1.41 & 2.04 & $2.22 \times 10^{-8}$ & 987 \\
\hline Coronary Artery Calcified Plaque (mass score) & 2.01 & 1.7 & 2.37 & $1.11 \times 10^{-16}$ & 968 & 2.47 & 1.91 & 3.21 & $8.48 \times 10^{-12}$ & 952 \\
\hline Carotid Intima Media Thickness (mm) & 1.38 & 1.25 & 1.53 & $5.20 \times 10^{-10}$ & 928 & 1.42 & 1.24 & 1.63 & $7.32 \times 10^{-7}$ & 911 \\
\hline Total Cholesterol (mg/dL) & 1.01 & 0.91 & 1.13 & 0.796 & 1003 & 1 & 0.86 & 1.17 & 1 & 986 \\
\hline $\mathrm{HDL}(\mathrm{mg} / \mathrm{dL})$ & 0.93 & 0.82 & 1.05 & 0.228 & 1003 & 0.87 & 0.72 & 1.04 & 0.133 & 986 \\
\hline Triglycerides (mg/dL) & 1.01 & 0.9 & 1.14 & 0.841 & 1003 & 1.12 & 0.95 & 1.33 & 0.172 & 986 \\
\hline $\mathrm{LDL}(\mathrm{mg} / \mathrm{dL})$ & 1.05 & 0.94 & 1.17 & 0.413 & 928 & 0.93 & 0.79 & 1.1 & 0.396 & 912 \\
\hline Pulse Pressure $(\mathrm{mmHg})$ & 1.3 & 1.16 & 1.46 & $8.24 \times 10^{-6}$ & 1019 & 1.35 & 1.13 & 1.61 & $7.71 \times 10^{-4}$ & 1001 \\
\hline Mean Arterial Pressure $(\mathrm{mmHg})$ & 0.9 & 0.79 & 1.04 & 0.149 & 1019 & 0.95 & 0.76 & 1.2 & 0.685 & 1001 \\
\hline Estimated Glomerular Filtration Rate $\left(\mathrm{ml} / \mathrm{min} / 1.73 \mathrm{~m}^{2}\right)$ & 0.63 & 0.55 & 0.72 & $3.60 \times 10^{-11}$ & 1021 & 0.63 & 0.51 & 0.78 & $2.75 \times 10^{-5}$ & 1003 \\
\hline Urine Albumin:creatinine Ratio (mg/g) & 1.56 & 1.42 & 1.72 & $<1 \times 10^{-16}$ & 1000 & 1.76 & 1.54 & 2.01 & $<1 \times 10^{-16}$ & 982 \\
\hline QT Interval (ms) & 1.02 & 0.91 & 1.16 & 0.709 & 985 & 1.13 & 0.93 & 1.38 & 0.212 & 968 \\
\hline High Blood Pressure Medications (\%) & 1.72 & 1.28 & 2.3 & $2.63 \times 10^{-4}$ & 1022 & 2.28 & 1.41 & 3.69 & $7.86 \times 10^{-4}$ & 1004 \\
\hline Statin Use (\%) & 0.88 & 0.7 & 1.11 & 0.293 & 1020 & 1.02 & 0.72 & 1.46 & 0.91 & 1002 \\
\hline Oral Hypoglycemic Medications (\%) & 1.04 & 0.79 & 1.38 & 0.769 & 1022 & 1.02 & 0.67 & 1.54 & 0.942 & 1004 \\
\hline Insulin Use (\%) & 1.71 & 1.35 & 2.17 & $8.51 \times 10^{-6}$ & 1022 & 1.84 & 1.32 & 2.58 & $3.55 \times 10^{-4}$ & 1004 \\
\hline
\end{tabular}

Relationships assessed using univariate Cox proportional hazards models. Hazards ratios (HRs) are for a one standard deviation change in the predictor (continuous variables) or change in group assignment (dichotomous variables). For medication use HRs, the HRs are for risk of mortality among those individuals using the given medication class. $\mathrm{Cl}$, Confidence Interval 
Table 3 Models selected for all-cause and cardiovascular disease (CVD) mortality in European Americans with type 2 diabetes

\begin{tabular}{|c|c|c|c|c|}
\hline Trait & Hazard Ratio & \multicolumn{2}{|c|}{$95 \%$ Hazard Ratio Confidence Interval } & $p$-value \\
\hline \multicolumn{5}{|l|}{ All-cause mortality } \\
\hline Age & 1.72 & 1.46 & 2.02 & $6.46 \times 10^{-11}$ \\
\hline Female Sex & 0.93 & 0.71 & 1.21 & 0.565 \\
\hline Urine Albumin:creatinine Ratio & 1.37 & 1.23 & 1.53 & $2.23 \times 10^{-8}$ \\
\hline Coronary Artery Calcified Plaque & 1.48 & 1.20 & 1.81 & $2.03 \times 10^{-4}$ \\
\hline Current Smoking & 1.79 & 1.30 & 2.46 & $3.38 \times 10^{-4}$ \\
\hline Insulin Use & 1.50 & 1.16 & 1.93 & 0.002 \\
\hline Educational Attainment & 0.76 & 0.65 & 0.91 & 0.002 \\
\hline \multicolumn{5}{|l|}{ CVD mortality } \\
\hline Age & 1.57 & 1.18 & 2.08 & 0.002 \\
\hline Female Sex & 0.94 & 0.63 & 1.40 & 0.756 \\
\hline Urine Albumin:creatinine Ratio & 1.51 & 1.31 & 1.74 & $1.99 \times 10^{-8}$ \\
\hline Coronary Artery Calcified Plaque & 1.71 & 1.23 & 2.38 & 0.001 \\
\hline Triglycerides & 1.28 & 1.05 & 1.56 & 0.017 \\
\hline History of Cardiovascular Disease & 1.59 & 1.03 & 2.46 & 0.036 \\
\hline
\end{tabular}

Models were selected using backward elimination, forward selection, and stepwise selection. Age and sex were forced into all models. Hazards ratios (HRs) are for a one standard deviation change in the predictor (continuous variables) or change in group assignment (dichotomous variables). For medication use HRs, the HRs are for risk of mortality among those individuals using the given medication class

where the dataset was randomly split by family into roughly equal halves. The analysis for the full sample was repeated separately in each random dataset. In each random dataset, demographic and clinical factors were selected to include in model building based on their univariate associations with all-cause or CVD mortality (Additional file 1). Models were selected using forward, backward, and stepwise selections for all-cause and CVD mortality in random datasets 1 and 2 (Additional files 2 and 3 ). As the associated predictors selected from each dataset differed slightly, a combined model including factors selected in the final model for each dataset was created for both all-cause and CVD mortality. Therefore, from this two-fold cross-validation approach, the allcause mortality model included age, sex, CAC, UACR, diabetes duration, current smoking, educational attainment, insulin use, and WHR, while the CVD mortality model included age, sex, CAC, UACR, history of CVD events, and diabetes duration. The factors selected are similar to those observed using the full sample, which shows that the results are stable with no evidence of overfitting. This full model was fitted in both random datasets, with a basic model limited to age and sex also fitted as a comparison to the full model.

Predicted values were then derived in each randomly selected dataset using regression coefficients derived from fitting the model in the opposite dataset, allowing calculation of average AUC for each dataset (Table 4), both for the full model derived using the two-fold crossvalidation approach and a basic model including only age and sex. The full model significantly improved prediction of both all-cause and CVD mortality $(p<0.05)$ in both random datasets (Table 4). An estimate of AUC for the whole EA cohort was also derived by fitting the models derived using the two-fold cross-validation approach in the whole sample, with an AUC of 0.788 for the full allcause mortality model in the whole sample, compared to 0.699 for a basic model containing only age and sex $(p=$ $6.50 \times 10^{-9}$ for improved prediction using the full model). Similarly, the full CVD mortality model had an AUC of 0.764, compared to 0.652 for a basic model containing only age and sex $\left(p=4.14 \times 10^{-7}\right.$ for improved prediction using the full model) (Table 4).

Factors which were predictors of mortality in the DHS in previous analyses, such as CRP [4] and biventricular volume [5], were not included in the main model selection due to lower sample size $(n=848$ for CRP, $n=771$ for biventricular volume). When adding biventricular volume to the full all-cause and CVD mortality models selected using a two-fold cross-validation approach, biventricular volume was nominally associated with increased all-cause mortality risk $(\mathrm{HR}=1.21$ for a SD change, $p=0.053)$ (Table 5) and more strongly associated with CVD mortality risk (HR $=1.52$ for a SD change, $p=0.002)$ (Table 6$)$. In contrast, CRP was a significant predictor when added to the all-cause mortality model ( $\mathrm{HR}=1.30$ for a SD change, $p=0.001$ ) (Table 5), but not the CVD mortality model $(\mathrm{HR}=1.19$ for a SD change, $p=0.167)$ (Table 6).

\section{Discussion}

This set of DHS analyses highlights demographic and clinical factors independently predictive of mortality in 
Table 4 Average area under the receiver operating characteristic curve (AUC) for the all-cause and cardiovascular disease (CVD) mortality models

\begin{tabular}{llllll}
\hline Data & Outcome & Model & AUC & $95 \%$ Confidence Interval & $p$-value \\
\hline Random 1 & All-cause mortality & Basic & 0.697 & $(0.644,0.749)$ & 0.011 \\
& All-cause mortality & Full & 0.759 & $(0.710,0.807)$ & 0.002 \\
& CVD mortality & Basic & 0.658 & $(0.590,0.726)$ & $(0.705,0.823)$ \\
Random 2 & CVD mortality & Full & 0.764 & $(0.638,0.747)$ & 0.0001 \\
& All-cause mortality & Basic & 0.693 & $(0.732,0.823)$ \\
& All-cause mortality & Full & 0.777 & $(0.534,0.694)$ \\
& CVD mortality & Basic & 0.614 & $(0.661,0.789)$ \\
& CVD mortality & Full Cohort & Basic & 0.725 & $(0.661,0.737)$ \\
& All-cause mortality & Full & 0.699 & $(0.756,0.821)$ \\
& All-cause mortality & Basic & 0.788 & $(0.600,0.704)$ \\
\hline
\end{tabular}

These models were derived using a two-fold cross-validation approach in each randomly selected dataset and in the full cohort. Basic models included age and sex only. Full models for all-cause mortality included age, sex, coronary artery calcified plaque, urine albumin:creatinine ratio, diabetes duration, current smoking, educational attainment, insulin use, and waist hip ratio. Full models for CVD mortality included age, sex, coronary artery calcified plaque, urine albumin:creatinine ratio, history of CVD events, and diabetes duration. $P$-values for comparing the predictive power of the basic model with the full model are listed

EAs with T2D. Most prior mortality model analyses in individuals with T2D have included a more limited set of clinical and demographic factors, for example BMI, lipids, medications, glycemic control, and eGFR, compared to those available in the DHS. As such, the literature does not fully address which factors may predict all-cause and CVD mortality by considering novel predictors, particularly CAC, in individuals with T2D. All the clinical and demographic factors included in model selection can be hypothesized to contribute to mortality. Our analysis shows, out of many mortality associated predictors, which ones are the most important to consider in T2D-affected individuals using a statistical model selection approach. While results from model selection for all-cause and CVD mortality differed slightly between model selection using the full cohort and model selection using a two-fold crossvalidation approach, the key factors selected, notably CAC and UACR, did not differ. This demonstrates the validity of model selection results. Other factors selected using the full sample, such as current smoking, insulin use, and educational attainment with all-cause mortality and history of cardiovascular disease with CVD mortality, were also included in the models selected using a two-fold crossvalidation approach. This indicates results from the model selection are stable and reveals important factors to consider in future analyses of mortality in community-based cohorts of T2D-affected individuals.

The two factors most consistently associated with allcause and CVD mortality were CAC and albuminuria. Prior studies in T2D have demonstrated striking associations of UACR with renal end-points, CVD events, CVD mortality, and all-cause mortality [18-20]. Prior mortality analyses with shorter follow-up in the full DHS cohort with and without T2D (83.7 \% T2D-affected) also found UACR to be associated with all-cause and CVD mortality, independent from CAC and other CVD risk factors such as age, sex, T2D affection status, BMI, current smoking, hypertension, dyslipidemia, renin-angiotensin system blocking medications, and prior CVD [7]. As in prior analyses of individuals with T2D [19], UACR was a stronger predictor of CVD mortality than eGFR in our models. UACR is a marker of generalized endothelial dysfunction, more so than kidney disease specifically, which is better reflected by changes in eGFR. UACR was not assessed in some analyses building mortality prediction models in T2D $[11,12]$, but it was selected as a significant predictor of elevated all-cause mortality in the Hong Kong Diabetes Registry cohort [13] and the Gargano Mortality Study [14]. The incorporation of CAC significantly improves mortality risk prediction, which is expected. CAC is a strong independent predictor of CVD events and mortality in the general population and in T2D [2, 3, 21-27], with individuals affected by diabetes tending to have higher CAC [28]. Recent model building using participants with T2D from the Multi-Ethnic Study of Atherosclerosis (MESA) and the Heinz Nixdorf Recall Study found that using CAC improved risk prediction for incident CVD events, an important contributor to mortality risk in those with T2D, above the Framingham or United Kingdom Prospective Diabetes study risk models which include more conventional risk factors such as age, sex, systolic blood pressure, $\mathrm{HbA}_{1 \mathrm{c}}$, and lipid levels [9]. Notably, carotid IMT, another novel predictor of CVD risk in T2D, was not selected for in these CVD event prediction models in T2D [9], consistent with our finding that IMT was not an independent predictor of mortality in the DHS 
Table 5 Addition of C-reactive protein and biventricular volume to model selected for all-cause mortality

\begin{tabular}{|c|c|c|c|c|c|c|c|c|c|c|c|c|c|c|}
\hline \multirow{2}{*}{$\begin{array}{l}\text { Trait } \\
\\
\text { Age }\end{array}$} & \multirow{2}{*}{$\begin{array}{l}\text { Hazard Ratio } \\
1.67\end{array}$} & \multicolumn{2}{|c|}{$\begin{array}{l}95 \% \\
\text { Hazard } \\
\text { Ratio } \\
\text { Confidence } \\
\text { Interval }\end{array}$} & \multirow{2}{*}{$\begin{array}{l}p \text {-value } \\
3.68 \times 10^{-10}\end{array}$} & \multirow{2}{*}{$\begin{array}{l}\text { Trait } \\
\text { Age }\end{array}$} & \multirow{2}{*}{$\begin{array}{l}\text { Hazard Ratio } \\
1.80\end{array}$} & \multicolumn{2}{|c|}{$\begin{array}{l}95 \% \text { Hazard Ratio } \\
\text { Confidence Interval }\end{array}$} & \multirow{2}{*}{$\begin{array}{l}p \text {-value } \\
6.54 \times 10^{-12}\end{array}$} & \multirow{2}{*}{$\begin{array}{l}\text { Trait } \\
\text { Age }\end{array}$} & \multirow{2}{*}{$\begin{array}{l}\text { Hazard Ratio } \\
1.81\end{array}$} & \multicolumn{2}{|c|}{$\begin{array}{l}95 \% \\
\text { Hazard } \\
\text { Ratio } \\
\text { Confidence } \\
\text { Interval }\end{array}$} & \multirow{2}{*}{$\begin{array}{l}p \text {-value } \\
9.65 \times 10^{-12}\end{array}$} \\
\hline & & 1.42 & 1.96 & & & & 1.52 & 2.13 & & & & 1.53 & 2.15 & \\
\hline Female Sex & 0.92 & 0.70 & 1.22 & 0.581 & Female Sex & 0.86 & 0.62 & 1.19 & 0.356 & Female Sex & 1.24 & 0.85 & 1.81 & 0.269 \\
\hline $\begin{array}{l}\text { Coronary Artery } \\
\text { Calcified Plaque }\end{array}$ & 1.50 & 1.24 & 1.81 & $3.32 \times 10^{-5}$ & $\begin{array}{l}\text { Coronary Artery } \\
\text { Calcified Plaque }\end{array}$ & 1.44 & 1.17 & 1.77 & 0.001 & $\begin{array}{l}\text { Coronary Artery } \\
\text { Calcified Plaque }\end{array}$ & 1.45 & 1.15 & 1.82 & 0.001 \\
\hline $\begin{array}{l}\text { Urine Albumin: } \\
\text { creatinine Ratio }\end{array}$ & 1.35 & 1.21 & 1.51 & $1.10 \times 10^{-7}$ & $\begin{array}{l}\text { Urine Albumin: } \\
\text { creatinine Ratio }\end{array}$ & 1.35 & 1.20 & 1.52 & $7.85 \times 10^{-7}$ & $\begin{array}{l}\text { Urine Albumin: } \\
\text { creatinine Ratio }\end{array}$ & 1.32 & 1.17 & 1.49 & $8.08 \times 10^{-6}$ \\
\hline $\begin{array}{l}\text { Diabetes } \\
\text { Duration }\end{array}$ & 1.10 & 0.96 & 1.26 & 0.173 & Diabetes Duration & 1.05 & 0.91 & 1.21 & 0.505 & Diabetes Duration & 1.09 & 0.94 & 1.25 & 0.261 \\
\hline Current Smoking & 1.70 & 1.25 & 2.31 & $7.38 \times 10^{-4}$ & Current Smoking & 1.63 & 1.16 & 2.28 & 0.005 & Current Smoking & 2.00 & 1.42 & 2.83 & $8.46 \times 10^{-5}$ \\
\hline $\begin{array}{l}\text { Educational } \\
\text { Attainment }\end{array}$ & 0.79 & 0.67 & 0.93 & 0.004 & $\begin{array}{l}\text { Educational } \\
\text { Attainment }\end{array}$ & 0.79 & 0.66 & 0.94 & 0.010 & Educational Attainment & 0.78 & 0.65 & 0.94 & 0.008 \\
\hline Insulin Use & 1.40 & 1.07 & 1.84 & 0.015 & Insulin Use & 1.49 & 1.11 & 2.00 & 0.008 & Insulin Use & 1.39 & 1.03 & 1.86 & 0.029 \\
\hline \multirow[t]{2}{*}{ Waist Hip Ratio } & 1.01 & 0.86 & 1.19 & 0.913 & Waist Hip Ratio & 0.97 & 0.81 & 1.17 & 0.765 & Waist Hip Ratio & 1.01 & 0.86 & 1.20 & 0.868 \\
\hline & & & & & C-reactive Protein & 1.30 & 1.11 & 1.52 & 0.001 & Biventricular Volume & 1.21 & 1.00 & 1.48 & 0.053 \\
\hline
\end{tabular}

The all-cause mortality model was selected using a two-fold cross-validation approach in European American participants with type 2 diabetes. Hazards ratios (HRs) are for a one standard deviation change in the predictor (continuous variables) or change in group assignment (dichotomous variables). For medication use HRs, the HRs are for risk of mortality among those individuals using the given medication class 
Table 6 Addition of C-reactive protein and biventricular volume to model selected for cardiovascular disease mortality

\begin{tabular}{|c|c|c|c|c|c|c|c|c|c|c|c|c|c|c|}
\hline \multirow{2}{*}{$\begin{array}{l}\text { Trait } \\
\\
\text { Age }\end{array}$} & \multirow{2}{*}{$\begin{array}{l}\text { Hazard Ratio } \\
\\
1.36\end{array}$} & \multicolumn{2}{|c|}{$\begin{array}{l}95 \% \\
\text { Hazard } \\
\text { Ratio } \\
\text { Confidence } \\
\text { Interval }\end{array}$} & \multirow{2}{*}{$\begin{array}{l}p \text {-value } \\
0.010\end{array}$} & \multirow{2}{*}{$\begin{array}{l}\text { Trait } \\
\text { Age }\end{array}$} & \multirow{2}{*}{$\begin{array}{l}\text { Hazard Ratio } \\
\\
1.63\end{array}$} & \multicolumn{2}{|c|}{$\begin{array}{l}95 \% \text { Hazard } \\
\text { Ratio } \\
\text { Confidence } \\
\text { Interval }\end{array}$} & \multirow{2}{*}{$\begin{array}{l}p \text {-value } \\
1.20 \times 10^{-4}\end{array}$} & \multirow{2}{*}{$\begin{array}{l}\text { Trait } \\
\\
\text { Age }\end{array}$} & \multirow{2}{*}{$\begin{array}{l}\text { Hazard Ratio } \\
\\
1.75\end{array}$} & \multicolumn{2}{|c|}{$\begin{array}{l}95 \% \text { Hazard Ratio } \\
\text { Confidence Interval }\end{array}$} & \multirow{2}{*}{$\begin{array}{l}p \text {-value } \\
1.66 \times 10^{-5}\end{array}$} \\
\hline & & 1.08 & 1.73 & & & & 1.27 & 2.10 & & & & 1.36 & 2.27 & \\
\hline Female Sex & 0.98 & 0.68 & 1.42 & 0.929 & Female Sex & 1.02 & 0.67 & 1.55 & 0.942 & Female Sex & 1.52 & 0.90 & 2.55 & 0.116 \\
\hline $\begin{array}{l}\text { Coronary Artery } \\
\text { Calcified Plaque }\end{array}$ & 1.67 & 1.24 & 2.26 & $7.18 \times 10^{-4}$ & $\begin{array}{l}\text { Coronary Artery } \\
\text { Calcified Plaque }\end{array}$ & 1.60 & 1.15 & 2.23 & 0.005 & $\begin{array}{l}\text { Coronary Artery } \\
\text { Calcified Plaque }\end{array}$ & 1.40 & 0.98 & 2.00 & 0.067 \\
\hline $\begin{array}{l}\text { Urine Albumin: } \\
\text { creatinine Ratio }\end{array}$ & 1.52 & 1.32 & 1.75 & $7.59 \times 10^{-9}$ & $\begin{array}{l}\text { Urine Albumin: } \\
\text { creatinine Ratio }\end{array}$ & 1.57 & 1.35 & 1.83 & $7.31 \times 10^{-9}$ & $\begin{array}{l}\text { Urine Albumin: } \\
\text { creatinine Ratio }\end{array}$ & 1.45 & 1.24 & 1.70 & $3.29 \times 10^{-6}$ \\
\hline $\begin{array}{l}\text { History of } \\
\text { Cardiovascular } \\
\text { Disease }\end{array}$ & 1.69 & 1.11 & 2.57 & 0.014 & $\begin{array}{l}\text { History of } \\
\text { Cardiovascular } \\
\text { Disease }\end{array}$ & 1.52 & 0.95 & 2.43 & 0.084 & $\begin{array}{l}\text { History of } \\
\text { Cardiovascular } \\
\text { Disease }\end{array}$ & 1.55 & 0.98 & 2.45 & 0.063 \\
\hline \multirow[t]{2}{*}{ Diabetes Duration } & 1.20 & 0.98 & 1.46 & 0.082 & Diabetes Duration & 1.04 & 0.84 & 1.28 & 0.736 & Diabetes Duration & 1.09 & 0.88 & 1.36 & 0.435 \\
\hline & & & & & C-reactive Protein & 1.19 & 0.93 & 1.51 & 0.167 & Biventricular Volume & 1.52 & 1.16 & 1.98 & 0.002 \\
\hline
\end{tabular}

The cardiovascular disease mortality model was selected using a two-fold cross-validation approach in European Americans with type 2 diabetes. Hazards ratios (HRs) are for a one standard deviation change in the predictor (continuous variables) or change in group assignment (dichotomous variables). For medication use HRs, the HRs are for risk of mortality among those individuals using the given medication class 
and previous literature indicating that $\mathrm{CAC}$ provides superior risk prediction and reclassification compared to carotid IMT $[29,30]$.

Demographic factors including current smoking, insulin use, and educational attainment were also associated with all-cause mortality in the DHS. Current smoking $[11,12]$ and use of insulin [11-14] have been previously included in prediction models as associated with elevated mortality risk in analyses of individuals with T2D. Lower educational attainment has also been associated with elevated mortality risk in prior assessments of T2D, although this was not always included in final selected models, potentially due to the inclusion of correlated variables such as income that were not used in our analysis [12]. History of CVD events being associated with CVD mortality is not surprising, given the elevated risk of secondary CVD events in those with established CVD. History of CVD is strongly associated with CAC burden $\left(p<1 \times 10^{-16}\right)$ but is still an independent predictor of CVD, but not all-cause, mortality.

Additional factors not included in the primary model building analysis due to reduced sample size may also be important to mortality risk prediction in T2D. Previous analysis in the DHS with shorter mortality follow-up time suggested that biventricular volume significantly increased AUC for prediction of all-cause and CVD mortality versus a model including age, sex, and CAC alone [5]. This is substantiated by data from this analysis, with biventricular volume improving prediction of CVD mortality (Table 6). Biventricular volume can be derived from the same CT scans used to evaluate CAC, but it appears to be predictive of CVD mortality independent of CAC burden, so this may be an important factor to include in future analyses of mortality in T2D. CRP may also need to be considered in future analyses. In a previously published analysis from the DHS, each one unit increase in log transformed CRP was associated with a 1.5-fold increase in risk for all-cause mortality (HR 1.54; $95 \%$ CI 1.33-1.77) [4]. Similar results were observed, though with a slightly attenuated HR, when CRP was added to our full all-cause mortality model from this analysis (Table 5). The lack of association with CVD mortality for CRP may not be surprising, as some studies have cast doubt on the causal role of CRP in CVD events [31].

Recent work in the DHS highlighted demographic and clinical factors associated with mortality in individuals with T2D at very high CVD risk based on a CAC score $>1000$, with, for example, higher $\mathrm{HbA}_{1 \mathrm{c}}$, longer diabetes duration, reduced kidney function, reduced use of statins, and higher CRP associated with higher mortality [32]. We attempted to perform model selection in only T2D affected individuals with CAC $>1000$ using similar methods to the analysis in the full T2D-affected DHS sample (data not shown). Models were not perfectly concordant between forward, backward, and stepwise selection, not surprisingly given the reduced sample size $(n=371)$, but selected models all included CAC, UACR, and $\mathrm{HbA}_{1 \mathrm{c}}$ as contributors to elevated risk of all-cause and CVD mortality in this very high risk sample, similar to the results in the full T2D-affected cohort with the exception of $\mathrm{HbA}_{1 \mathrm{c}}$, which was not selected in the full T2D-affected cohort but appears to be a more important predictor in the CAC $>1000$ subgroup.

Limitations of the current analysis include the lack of a replication cohort with similar mortality data and demographic and clinical factors assessed, necessitating use of a two-fold cross-validation approach. There are, however, few studies with the same breadth of data in a population-based sample of individuals with T2D. The latter, we believe, is an important feature of the DHS since it likely reflects what actually influences mortality in the community, as opposed to in a clinical trial. Previous analyses have been performed in cohorts with different recruitment strategies than the DHS, for example population-based cohorts in Hong Kong [13] and Italy [14], or cohorts extracted from electronic medical record data whose diabetes was not as well characterized as the DHS and with exclusions based on medication use [11]. None of these cohorts had data on all the novel measures of CVD risk available in the DHS. Length of follow-up, over 9 years on average, was also greater than in previous analyses [11-14], as was duration of T2D in study participants $[13,14]$. This long follow-up does mean that some clinical guidelines and practices, for example recommendations for statin use in all individuals age 40-75 affected by diabetes [33], have changed since the DHS was initiated and may influence future mortality risk. Data for some demographic and clinical factors which predicted all-cause mortality in prior analyses in T2D, such as cancer [13] or Charlson index, a measure of comorbidity burden [12], were not available in the DHS, while some factors available in the DHS, notably $\mathrm{CAC}$, were not used in prior model selection, making direct comparisons of mortality models derived in T2Daffected individuals difficult.

Additional analytic limitations include the relatively small number of events, in particular for CVD mortality (14.3\% of the cohort), which necessitated use of only two-fold cross validation, as opposed to an analysis strategy splitting the cohort by family into a greater number of small random samples. Further validation of our risk prediction models in additional cohorts of T2D-affected patients would be necessary prior to clinical applications. While these results highlight factors that may be important for mortality risk assessment in the T2D-affected population, causal relationships are uncertain. The current analyses were limited to individuals of EA descent, since 
levels of CAC differ from those in African Americans; different factors may impact mortality risk in other ethnic groups.

\section{Conclusions}

The present results demonstrate the importance of assessing UACR and CAC in particular for prediction of CVD and all-cause mortality. Not all patients with T2D are at equal risk of poor health outcomes and mortality, and more comprehensive assessment in research and clinical settings of these predictors of mortality, particularly CAC, in T2D-affected individuals is needed.

\section{Additional files}

Additional file 1: Associations of demographic and clinical factors with all-cause and cardiovascular disease mortality in two randomly selected datasets from European Americans with type 2 diabetes. Associations with all-cause and cardiovascular disease mortality were assessed using univariate Cox proportional hazards models. Hazards ratios (HRs) are for a one standard deviation change in the predictor (continuous variables) or change in group assignment (dichotomous variables). For medication use HRs, the HRs are for risk of mortality among those individuals using the given medication class.

Additional file 2: Model selected for all-cause mortality using backward elimination, forward selection, and stepwise selection in two randomly selected datasets from European American participants with type 2 diabetes. Age and sex were forced into all models. Hazards ratios (HRs) are for a one standard deviation change in the predictor (continuous variables) or change in group assignment (dichotomous variables). For medication use HRs, the HRs are for risk of mortality among those individuals using the given medication class.

Additional file 3: Model selected for cardiovascular disease mortality using backward elimination, forward selection, and stepwise selection in two randomly selected datasets from European Americans with type 2 diabetes. Age and sex were forced into all models. Hazards ratios (HRs) are for a one standard deviation change in the predictor (continuous variables) or change in group assignment (dichotomous variables). For medication use HRs, the HRs are for risk of mortality among those individuals using the given medication class.

\section{Competing interests}

The authors declare that they have no competing interests.

\section{Authors' contributions}

LMR performed the statistical analysis and wrote the manuscript; F-CH helped design the statistical analysis and assisted with the manuscript preparation; AJC contributed to the statistical analysis and data management and reviewed the manuscript; JJC and BIF were involved in the initial design of the Diabetes Heart Study, contributed to patient ascertainment and clinical evaluation, and reviewed the manuscript; DWB leads the Diabetes Heart Study and assisted with the manuscript preparation. DWB is the guarantor of this work and had full access to all the data and takes responsibility for the integrity of the data and the accuracy of the data analysis. All authors read and approved the final manuscript.

\section{Acknowledgements}

The authors thank the other investigators, the staff, and the participants of the DHS study for their valuable contributions. This study was supported by the National Institutes of Health through R01 HL67348 and R01 HL092301 (to DWB), R01 AR48797 (to JJC), and F31 AG044879 (to LMR).

\section{Author details}

${ }^{1}$ Molecular Genetics and Genomics Program, Wake Forest School of Medicine, Winston-Salem, NC, USA. ${ }^{2}$ Center for Human Genomics, Wake
Forest School of Medicine, Winston-Salem, NC, USA. ${ }^{3}$ Center for Diabetes Research, Wake Forest School of Medicine, Winston-Salem, NC, USA ${ }^{4}$ Department of Biostatistical Sciences, Wake Forest School of Medicine, Winston-Salem, NC, USA. ${ }^{5}$ Department of Biochemistry, Wake Forest School of Medicine, Winston-Salem, NC, USA. ${ }^{6}$ Department of Radiology, Vanderbilt University Medical Center, Nashville, TN, USA. ${ }^{7}$ Department of Internal Medicine - Nephrology, Wake Forest School of Medicine, Winston-Salem, NC, USA. ${ }^{8}$ Center for Genomics and Personalized Medicine Research, Wake Forest School of Medicine, Medical Center Boulevard, Winston-Salem, NC 27157, USA.

Received: 19 March 2015 Accepted: 18 June 2015

Published online: 28 June 2015

\section{References}

1. Bowden D, Cox A, Freedman B, Hugenschimdt C, Wagenknecht L, Herrington D, et al. Review of the Diabetes Heart Study (DHS) family of studies: a comprehensively examined sample for genetic and epidemiological studies of type 2 diabetes and its complications. Rev Diabet Stud. 2010;7(3):188-201. doi:10.1900/rds.2010.7.188.

2. Agarwal S, Cox A, Herrington D, Jorgensen N, Xu J, Freedman B, et al. Coronary calcium score predicts cardiovascular mortality in diabetes: Diabetes Heart Study. Diabetes Care. 2013;36(4):972-7. doi:10.2337/dc12-1548.

3. Agarwal S, Morgan T, Herrington D, Xu J, Cox A, Freedman B, et al. Coronary calcium score and prediction of all-cause mortality in diabetes: the diabetes heart study. Diabetes Care. 2011;34(5):1219-24. doi:10.2337/dc11-0008.

4. Cox A, Agarwal S, M Herrington D, Carr J, Freedman B, Bowden D. C-reactive protein concentration predicts mortality in type 2 diabetes: the Diabetes Heart Study. Diabet Med. 2012;29(6):767-70. doi:10.1111/j.1464-5491.2011.03560.x.

5. Cox A, Hugenschmidt C, Wang P, Hsu F-C, Kenchaiah S, Daniel K, et al. Usefulness of Biventricular volume as a predictor of mortality in patients with diabetes mellitus (from the Diabetes Heart Study). Am J Cardiol. 2013;111(8):1152-8. doi:10.1016/.amjcard.2012.12.044.

6. Cox AJ, Azeem A, Yeboah J, Soliman EZ, Aggarwal SR, Bertoni AG, et al. Heart rate-corrected QT interval is an independent predictor of all-cause and cardiovascular mortality in individuals with type 2 diabetes: the Diabetes Heart Study. Diabetes Care. 2014:37(5):1454-61. doi:10.2337/dc13-1257.

7. Cox AJ, Hsu FC, Carr JJ, Freedman BI, Bowden DW. Glomerular filtration rate and albuminuria predict mortality independently from coronary artery calcified plaque in the Diabetes Heart Study. Cardiovasc Diabetol. 2013;12:68. doi:10.1186/1475-2840-12-68.

8. van Dieren S, Beulens JW, Kengne AP, Peelen LM, Rutten GE, Woodward M, et al. Prediction models for the risk of cardiovascular disease in patients with type 2 diabetes: a systematic review. Heart. 2012;98(5):360-9. doi:10.1136/heartjnl-2011-300734.

9. Yeboah J, Erbel R, Delaney JC, Nance R, Guo M, Bertoni AG, et al. Development of a new diabetes risk prediction tool for incident coronary heart disease events: the Multi-Ethnic Study of Atherosclerosis and the Heinz Nixdorf Recall Study. Atherosclerosis. 2014;236(2):411-7. doi:10.1016/ j.atherosclerosis.2014.07.035.

10. Go AS, Mozaffarian D, Roger VL, Benjamin EJ, Berry JD, Borden WB, et al. Heart disease and stroke statistics - 2013 update: a report from the American Heart Association. Circulation. 2013;127(1):e6-245. doi:10.1161/ CIR.0b013e31828124ad.

11. Wells BJ, Jain A, Arrigain S, Yu C, Rosenkrans WA, Kattan MW. Predicting 6-year mortality risk in patients with type 2 diabetes. Diabetes Care. 2008:31(12):2301-6. doi:10.2337/dc08-1047.

12. McEwen LN, Karter AJ, Waitzfelder BE, Crosson JC, Marrero DG, Mangione $\mathrm{CM}$, et al. Predictors of mortality over 8 years in type 2 diabetic patients: Translating Research Into Action for Diabetes (TRIAD). Diabetes Care. 2012;35(6):1301-9. doi:10.2337/dc11-2281.

13. Yang X, So WY, Tong PC, Ma RC, Kong AP, Lam CW, et al. Development and validation of an all-cause mortality risk score in type 2 diabetes. Arch Intern Med. 2008;168(5):451-7. doi:10.1001/archinte.168.5.451.

14. De Cosmo S, Copetti M, Lamacchia O, Fontana A, Massa M, Morini E, et al. Development and validation of a predicting model of all-cause mortality in patients with type 2 diabetes. Diabetes Care. 2013;36(9):2830-5. doi:10.2337/ dc12-1906.

15. Levey AS, Stevens LA, Schmid CH, Zhang YL, Castra 3rd AF, Feldman HI, et al. A new equation to estimate glomerular filtration rate. Ann Intern Med. 2009;150(9):604-12. doi:10.7326/0003-4819-150-9-200905050-00006. 
16. Carr JJ, Nelson JC, Wong ND, MCNitt-Gray M, Arad Y, Jacobs Jr DR, et al. Calcified coronary artery plaque measurement with cardiac $C T$ in population-based studies: standardized protocol of Multi-Ethnic Study of Atherosclerosis (MESA) and Coronary Artery Risk Development in Young Adults (CARDIA) study. Radiology. 2005;234(1):35-43. doi:10.1148/ radiol.2341040439.

17. Carr JJ, Crouse 3rd JR, Goff Jr DC, D'Agostino Jr RB, Peterson NP, Burke GL. Evaluation of subsecond gated helical $\mathrm{CT}$ for quantification of coronary artery calcium and comparison with electron beam CT. AJR Am J Roentgenol. 2000;174(4):915-21. doi:10.2214/ajr.174.4.1740915.

18. Wada T, Haneda M, Furuichi K, Babazono T, Yokoyama H, Iseki K, et al. Clinical impact of albuminuria and glomerular filtration rate on renal and cardiovascular events, and all-cause mortality in Japanese patients with type 2 diabetes. Clin Exp Nephrol. 2014;18(4):613-20. doi:10.1007/s10157-013-0879-4.

19. Ninomiya T, Perkovic V, de Galan BE, Zoungas S, Pillai A, Jardine M, et al. Albuminuria and kidney function independently predict cardiovascular and renal outcomes in diabetes. J Am Soc Nephrol. 2009;20(8):1813-21. doi:10.1681/asn.2008121270.

20. Fox CS, Matsushita K, Woodward M, Bilo HJ, Chalmers J, Heerspink HJ, et al. Associations of kidney disease measures with mortality and end-stage renal disease in individuals with and without diabetes: a meta-analysis. Lancet. 2012;380(9854):1662-73. doi:10.1016/s0140-6736(12)61350-6.

21. Folsom A, Kronmal R, Detrano R, O'Leary D, Bild D, Bluemke D, et al. Coronary artery calcification compared with carotid intima-media thickness in the prediction of cardiovascular disease incidence: the Multi-Ethnic Study of Atherosclerosis (MESA). Arch Intern Med. 2008;168(12):1333-9. doi:10.1001/archinte.168.12.1333.

22. Detrano R, Guerci A, Carr J, Bild D, Burke G, Folsom A, et al. Coronary calcium as a predictor of coronary events in four racial or ethnic groups. N Engl J Med. 2008;358(13):1336-45. doi:10.1056/NEJMoa072100.

23. Raggi P, Shaw LJ, Berman DS, Callister TQ. Prognostic value of coronary artery calcium screening in subjects with and without diabetes. J Am Coll Cardiol. 2004;43(9):1663-9. doi:10.1016/j.jacc.2003.09.068.

24. Polonsky TS, McClelland RL, Jorgensen NW, Bild DE, Burke GL, Guerci AD, et al. Coronary artery calcium score and risk classification for coronary heart disease prediction. JAMA. 2010;303(16):1610-6. doi:10.1001/ jama.2010.461

25. Erbel R, Mohlenkamp S, Moebus S, Schmermund A, Lehmann N, Stang A, et al. Coronary risk stratification, discrimination, and reclassification improvement based on quantification of subclinical coronary atherosclerosis: the Heinz Nixdorf Recall study. J Am Coll Cardiol. 2010;56(17):1397-406. doi:10.1016/j.jacc.2010.06.030.

26. Elias-Smale SE, Proenca RV, Koller MT, Kavousi M, van Rooij FJ, Hunink MG, et al. Coronary calcium score improves classification of coronary heart disease risk in the elderly: the Rotterdam study. J Am Coll Cardiol. 2010;56(17):1407-14. doi:10.1016/j.jacc.2010.06.029.

27. Kramer CK, Zinman B, Gross JL, Canani LH, Rodrigues TC, Azevedo MJ, et al. Coronary artery calcium score prediction of all cause mortality and cardiovascular events in people with type 2 diabetes: systematic review and meta-analysis. BMJ. 2013;346:f1654. doi:10.1136/bmj.f1654.

28. Hoff J, Quinn L, Sevrukov A, Lipton R, Daviglus M, Garside D, et al. The prevalence of coronary artery calcium among diabetic individuals without known coronary artery disease. J Am Coll Cardiol. 2003;41(6):1008-12. doi:10.1016/S0735-1097(02)02975-3.

29. Yeboah J, McClelland R, Polonsky T, Burke G, Sibley C, O'Leary D, et al. Comparison of novel risk markers for improvement in cardiovascular risk assessment in intermediate-risk individuals. JAMA. 2012;308(8):788-95. doi:10.1001/jama.2012.9624

30. Ferket BS, van Kempen BJ, Hunink MG, Agarwal I, Kavousi M, Franco OH, et al. Predictive value of updating Framingham risk scores with novel risk markers in the U.S. general population. PLoS One. 2014;9(2), e88312. doi:10.1371/journal.pone.0088312

31. Wensley F, Gao P, Burgess S, Kaptoge S, Di Angelantonio E, Shah T, et al. Association between $C$ reactive protein and coronary heart disease: mendelian randomisation analysis based on individual participant data. BMJ. 2011;342:d548. doi:10.1136/bmj.d548.

32. Cox AJ, Hsu FC, Freedman BI, Herrington DM, Criqui MH, Carr JJ, et al. Contributors to mortality in high-risk diabetic patients in the Diabetes Heart Study. Diabetes Care. 2014;37(10):2798-803. doi:10.2337/dc14-0081.
33. Stone NJ, Robinson JG, Lichtenstein AH, Bairey Merz CN, Blum CB, Eckel RH, et al. 2013 ACC/AHA guideline on the treatment of blood cholesterol to reduce atherosclerotic cardiovascular risk in adults: a report of the American College of Cardiology/American Heart Association Task Force on Practice Guidelines. J Am Coll Cardiol. 2014;63(25 Pt B):2889-934. doi:10.1016/ j.jacc.2013.11.002.

\section{Submit your next manuscript to BioMed Central and take full advantage of:}

- Convenient online submission

- Thorough peer review

- No space constraints or color figure charges

- Immediate publication on acceptance

- Inclusion in PubMed, CAS, Scopus and Google Scholar

- Research which is freely available for redistribution 